\title{
Clustering Data Kredit Bank Menggunakan Algoritma Agglomerative Hierarchical Clustering Average Linkage
}

\author{
${ }^{1}$ Ginanjar Abdurrahman \\ ${ }^{1}$ Universitas Muhammadiyah Jember \\ Email: ${ }^{1}$ abdurrahmanginanjar@gmail.com
}

(Naskah masuk: 15 Desember 2108, diterima untuk diterbitkan:29 desember 2018)

\begin{abstract}
ABSTRAK
Data mining adalah pengembangan model yang merepresentasikan penemuan pola menggunakan data historis. Model dapat diaplikasikan pada data untuk prediksi (klasifikasi dan regresi), segmentasi populasi (clustering), dan menentukan hubungan di dalam populasi (asosiasi). Dari beberapa model, salah satunya adalah clustering yang didefinisikan sebagai proses mengorganisir objek-objek menjadi satu kelompok yang anggotanya memiliki kemiripan tertentu. Similaritas ada dua, yakni similaritas berdasarkan bentuk dan jarak. Clustering mempunyai beberapa karakteristik, yaitu: partitioning, hierarchical, overlapping, dan hybrid. Hierarchical clustering adalah salah satu algoritma clustering dengan karakteristik setiap data harus termasuk dalam cluster tertentu, dan data yang termasuk dalam cluster tertentu tidak dapat berpindah ke cluster lain. Hierarchical clustering ada dua, yaitu divisive (top to down) dan agglomerative (down to top). Algoritma agglomerative ada empat yaitu single linkage, centroid linkage, complete linkage, dan average linkage. Salah satu dari algoritma agglomerative tersebut adalah average linkage. Algoritma ini merupakan algoritma terbaik di antara algoritma hierarchical yang lain, tetapi memiliki waktu komputasi tertinggi. Pada penelitian ini akan dilakukan clustering terhadap nasabah di suatu bank dengan algoritma agglomerative hierarchical clustering average linkage. Atribut data yang digunakan: status pengecekan, durasi kredit, sejarah kredit, tujuan kredit, besaran kredit, status tabungan, employment, komitmen, status personal, pihak lain, menetap sejak, kepemilikan property, umur, rencana pembayaran lainnya, status rumah, keberadaan kredit, pekerjaan, jumlah tanggungan, telepon rumah, pekerja luar negeri, dan kelas. Data dalam penelitian ini sebanyak 1000 instances, yang kemudian dijadikan sebagai data training sebanyak $25 \%, 50 \%$, dan $75 \%$, sedangkan untuk data testing digunakan keseluruhan data.
\end{abstract}

Kata kunci : Data mining, Dataset, Clustering, Agglomerative Hierarchical Clustering, Average Linkage

\begin{abstract}
Data mining is the development of model that represents pattern discovery using historical data. The model can be applied to data for prediction (classification and regression), population segmentation (clustering), and determining relationships within the population (association). Of the several models, one of them is clustering which is defined as the process of organizing objects into one group whose members have similarities. There are two similarities, namely similarity based on shape and distance. Clustering has several characteristics, namely: partitioning, hierarchical, overlapping, and hybrid. Hierarchical clustering is a clustering algorithm with the characteristics of each data must be included in a particular cluster, and data included in a particular cluster cannot moved to another cluster. There are two hierarchical clustering, namely divisive (top to down) and agglomerative (down to top). There are four agglomerative algorithms, namely single linkage, centroid linkage, complete linkage, and average linkage. One of the agglomerative is average linkage. This algorithm is the best hierarchical algorithms, but has the highest computational time. In this study clustering of customers in a bank conducted with the agglomerative hierarchical clustering average linkage. Data attributes used: checking status, credit duration, credit history, credit goals, loan size,
\end{abstract}


savings status, employment, commitment, personal status, other parties, settled since, property ownership, age, other payment plans, home status, credit availability, employment, number of dependents, landline, overseas workers and class. The data in this study were 1000 instances, which were then used as training data for $25 \%, 50 \%$, and $75 \%$, while for the testing data the entire data.

Keywords: Data mning, datasets, clustering, agglomerative hierarchical clustering, average linkage.

\section{PENDAHULUAN}

Data mining adalah proses penemuan pola dan hubungan dalam data (Hornick, Marcade \& Venkayala, 2007:6). Selain itu, Hornick, Marcade \& Venkayala (2007:6) juga mengemukakan bahwa data mining merupakan pengembangan model yang secara khusus merepresentasikan penemuan pola menggunakan data historis. Model dapat diaplikasikan pada data untuk prediksi (klasifikasi dan regresi), segmentasi populasi (clustering), dan menentukan hubungan di dalam populasi (asosiasi).

Dari beberapa model yang dapat diaplikasikan pada data, salah satunya adalah segmentasi populasi, dalam hal ini adalah clustering (pengelompokan). Clustering didefinisikan sebagai suatu proses mengorganisir objek-objek menjadi satu kelompok yang anggotanya memiliki similaritas (kemiripan) tertentu. Similaritas dibedakan menjadi dua, yakni similaritas berdasarkan bentuk dan similaritas berdasarkan jarak.

Clustering mempunyai beberapa karakteristik, yaitu: partitioning clustering, hierarchical clustering, overlapping clustering, dan hybrid. Pada partitioning clustering, setiap data harus termasuk pada cluster tertentu. Di samping itu, pada partitioning clustering, setiap data yang termasuk cluster tertentu pada suatu iterasi mempunyai kemungkinan berpindah ke cluster lain pada iterasi berikutnya. Overlapping clustering, setiap data mempunyai kemungkinan termasuk ke dalam beberapa cluster, atau dengan kata lain, data mempunyai nilai keanggotaan pada beberapa cluster. Yang ketiga adalah hierarchical clustering, yakni setiap data harus termasuk dalam cluster tertentu, dan data yang termasuk dalam cluster tertentu pada suatu iterasi, tidak dapat berpindah ke cluster lain. Karakteristik yang keempat adalah hybrid, yakni menggabungkan karakteristik partitioning, overlapping, dan hierarchical.

Algoritma hierarchical dibagi menjadi dua, yakni divisive (top to down) dan agglomerative (down to top). Di dalam algoritma agglomerative terdapat empat macam metode, yaitu: single linkage, centroid linkage, complete linkage, dan average linkage. Salah satu algoritma agglomerative yakni average linkage, yang selanjutnya dipilih sebagai algoritma di dalam penelitian ini, disebut sebagai algoritma agglomerative hierarchical clustering (ahc) average linkage. Algoritma ini dipilih karena merupakan algoritma terbaik di antara algoritma hierarchical yang lain walaupun dengan waktu komputasi tertinggi di antara algoritma hierarchical yang lain (Barakbah, 2006: 35).

Pada penelitian ini, akan dilakukan clustering terhadap nasabah di suatu bank dengan menggunakan algoritma agglomerative hierarchical clustering (ahc) average linkage. Adapun atribut data yang digunakan adalah: status pengecekan, durasi kredit, sejarah kredit, tujuan kredit, besaran kredit, status tabungan, 
employment, komitmen, status personal, pihak lain, menetap sejak, kepemilikan property, umur, rencana pembayaran lainnya, status rumah, keberadaan kredit, pekerjaan, jumlah tanggungan, telepon rumah, pekerja luar negeri, dan kelas. Data yang digunakan dalam penelitian ini sebanyak 1000 instances, Agar datasets dapat digunakan untuk clustering data harus dibersihkan terlebih dahulu dari outlier dan extreme value. Setelah data dibersihkan dari outlier dan extrema value, diperoleh data sebanyak 822 record data. Dari 822 record data tersebut kemudian dilakukan partisi data menggunakan metode remove percentage untuk data training. Partisi yang digunakan sebagai data training adalah $25 \%$ data, $50 \%$ data, $75 \%$ data, sedangkan $100 \%$ data selanjutnya digunakan sebagai data testing..

Untuk mempermudah pekerjaan, berkaitan dengan banyaknya dataset yang ada, diperlukan suatu program aplikasi untuk membantu penentuan clustering dataset kredit bank. Dalam hal ini, digunakan aplikasi weka 3.6 untuk mengcluster dataset, sehingga clustering dataset nantinya dapat ditemukan dengan metode agglomerative hierarchical clustering berdasarkan perhitungan weka 3.6 tersebut.

\section{METODE PENELITIAN}

Jenis penelitian ini adalah jenis penelitian kuantitatif, yaitu bernilai secara numerik atau dengan kata lain nilai-nilai peubah ini dinyatakan dalam bilangan real (Abadyo dan Hendro, 1999:3). Metode dalam penelitian ini adalah dengan mengimplementasikan algoritma $\mathrm{AHC}$ Average Linkage dengan menggunakan bantuan aplikasi weka 3.9.1. Adapun langkah-langkah dalam melakukan penelitian ini adalah sebagai berikut.

\subsection{Identifikasi Masalah}

Identifikasi masalah merupakan tahap awal dalam penelitian, yaitu dengan mengenali masalah yang ada apa saja serta menawarkan solusi yang dapat digunakan untuk menyelesaikan masalah tersebut.

\subsection{Studi Literatur}

Tahap ini merupakan tahap untuk mencari referensi berupa jurnal penelitian, paper, buku-buku referensi, serta referensi yang lain terkait dengan penelitian untuk melengkapi pengetahuan awal, guna memahami teori yang dapat digunakan untuk menunjang penelitian.

\subsection{Dataset}

Dataset diambil dari data simulasi yang sudah tersedia pada program weka 3.9.1 dengan source data: weka 3.9.1/data/german_credit.arff dengan record sebanyak 1000 instances. Agar datasets dapat digunakan untuk clustering data harus dibersihkan terlebih dahulu dari outlier dan extreme value. Setelah data dibersihkan dari outlier dan extrema value, diperoleh data sebanyak 822 record data. Dari 822 record data tersebut kemudian dilakukan partisi data menggunakan metode remove percentage untuk data training. Partisi yang digunakan sebagai data training adalah $25 \%$ data, $50 \%$ data, $75 \%$ data, sedangkan $100 \%$ data selanjutnya digunakan sebagai data testing. 


\subsection{Algoritma AHC Average Linkage}

Langkah-langkah algoritma AHC Average Linkage secara umum

1. Mencari jarak minimum dari dua objek.

2. Gabungkan dua objek dengan jarak minimum menjadi satu cluster

3. Cari jarak antar cluster dengan menggunakan rata-rata

4. Ulangi langkah 1-2 sampai semua objek bergabung menjadi satu cluster

\subsection{Interpretasi dan Evaluasi}

Tahap terakhir adalah melakukan interpretasi dan evaluasi. Pada tahap ini, informasi yang dihasilkan dari proses data mining perlu disajikan dalam bentuk yang mudah dimengerti oleh pihak yang berkepentingan.

\subsection{Simulasi Perhitungan Manual}

\section{Algoritma AHC Average Linkage}

Contoh Kasus:

Jika diketahui matrik jarak antara 5 objek yang disajikan pada Tabel 1.

Tabel 1. Jarak Antara 5 Objek

\begin{tabular}{cccccc}
\hline & A & B & C & D & E \\
\hline A & 0 & 1 & 5 & 6 & 8 \\
B & 1 & 0 & 3 & 8 & 7 \\
C & 5 & 3 & 0 & 4 & 6 \\
D & 6 & 8 & 4 & 0 & 2 \\
E & 8 & 7 & 6 & 2 & 0 \\
\hline
\end{tabular}

Langkah-langkah dalam algoritma AHC Average Linkage secara umum adalah sebagai berikut:
1. Mencari objek dengan jarak minimum

A dan B mempunyai jarak minimum, yaitu 1, maka objek $A$ dan $B$ bergabung menjadi satu cluster ( $A B)$.

2. Menghitung jarak antara cluster $A B$ dengan objek lainnya.

$d_{(A B) C}=$ Average $\left(d_{A C}, d_{B C}\right)=\frac{5+3}{2}=$ 4

$d_{(A B) D}=$ Average $\left(d_{A D}, d_{B D}\right)=$ $\frac{6+8}{2}=7$

$d_{(A B) E}=$ Average $\left(d_{A E}, d_{B E}\right)=$ $\frac{8+7}{2}=7.5$

Dengan demikian, terbentuk matrik jarak yang disajikan pada Tabel 2

Tabel 2: Matrik Jarak Baru:

\begin{tabular}{ccccc}
\hline & AB & C & D & E \\
\hline AB & 0 & 4 & 7 & 7.5 \\
C & 4 & 0 & 4 & 6 \\
D & 7 & 4 & 0 & 2 \\
E & 7.5 & 6 & 2 & 0 \\
\hline
\end{tabular}

Mencari jarak terdekat antara dua objek

D dan $E$ mempunyai jarak terdekat, yaitu 2. Maka objek $D$ dan $E$ bergabung menjadi satu cluster (DE).

$$
\begin{aligned}
& d_{(A B) C}=\text { Average }\left(d_{A C}, d_{B C}\right)=\frac{5+3}{2}=4 \\
& d_{(A B)(D E)}= \\
& \text { Average }\left(d_{A D}, d_{A E}, d_{B D}, d_{B E}\right)= \\
& \frac{6+8+8+7}{4}=\frac{29}{4}=6.75 \\
& d_{(D E) C}=\text { Average }\left(d_{D C}, d_{E C}\right)=\frac{4+6}{2}=5
\end{aligned}
$$

Dengan demikian matrik jarak barunya disajikan pada Tabel 3

Tabel 3: Matrik Jarak Baru 


\begin{tabular}{cccc}
\hline & AB & C & DE \\
\hline $\mathrm{AB}$ & 0 & 4 & 6.75 \\
$\mathrm{C}$ & 4 & 0 & 5 \\
$\mathrm{DE}$ & 6.75 & 5 & 0
\end{tabular}

4. Mencari jarak terdekat antara dua objek

$\mathrm{AB}$ dan $\mathrm{C}$ mempunyai jarak minimum yaitu 4, sehingga objek $A B$ dan $C$ bergabung menjadi satu cluster ( $A B C)$.

5. Pada langkah terakhir, cluster $A B C$ bergabung dengan DE sehingga terbentuk cluster tunggal (ABCDE).

\section{HASIL PENELITIAN}

Pada bagian ini akan dijelaskan mengenai hasil clustering menggunakan algoritma Agglomerative Hierarchical Clustering $(A H C)$ pada data kredit nasabah dengan bantuan aplikasi Weka 3.9.1. Hasil penelitian yang selanjutnya dibahas sebagai berikut.

\subsection{Persiapan Data (Preprocessing)}

Datasets yang digunakan adalah datasets dari program internal Weka 3.9.1 yang diperoleh dari direktori: "C:IWeka-39ldatalg-credit". Banyaknya record data yang akan digunakan dalam penelitian ini sebanyak 1000 record data nasabah kredit, dengan 21 atribut, yakni: checking status, duration, credit history, purpose, credit amount, savings status, employment, installment commitment, personal status, other parties, residence since, property magnitude, age, other payment plans, housing, existing credits, job, num dependents, own telephone, foreign worker, dan class.

Agar datasets dapat digunakan untuk clustering data harus dibersihkan terlebih dahulu dari outlier dan extreme value. Dari dataset awal yang berjumlah 1000 record data, terdeteksi sebanyak 25 data sebagai outlier dan 155 data sebagai extreme value. Outlier dan extreme value dihilangkan dengan menggunakan filter dengan metode Interquartile Range sehingga diperoleh sebanyak 822 record data yang sudah bersih dari outlier maupun extreme value.

\subsection{Skenario Uji Coba}

Dari 822 record data kemudian dilakukan partisi data menggunakan metode remove percentage untuk data training. Partisi yang digunakan sebagai data training adalah $25 \%$ data, $50 \%$ data, $75 \%$ data, sedangkan $100 \%$ data selanjutnya digunakan sebagai data testing. Remove percentage yang digunakan adalah remove percentage $75 \%$ untuk memperoleh data sebanyak $25 \%$, remove percentage sebesar $50 \%$ untuk memperoleh data sebanyak $50 \%$, dan remove percentage sebanyak $25 \%$ untuk memperoleh data sebanyak $70 \%$, dan data sebanyak $100 \%$ tanpa remove percentage. Masing-masing data tersebut, baik data training maupun data testing selanjutnya dibentuk menjadi 5 cluster dengan bantuan program aplikasi data mining Weka 3.9.1 menggunakan algoritma Agglomerative Hierarchical Clustering Average Linkage.

\subsection{Hasil dan Pembahasan}

Berikut ini adalah hasil uji coba menggunakan bantuan perangkat lunak Weka 3.9.1..

1. Data training sebanyak $25 \%$, dibentuk 5 cluster disajikan pada Tabel 4 berikut.

Tabel 4: Hasil clustering data training sebanyak $25 \%$

\begin{tabular}{cl}
\hline Cluster ke- & \multicolumn{1}{c}{$\begin{array}{c}\text { Jumlah anggota } \\
\text { cluster }\end{array}$} \\
\hline 1 & $195(95 \%)$ \\
2 & $3(1 \%)$ \\
3 & $2(1 \%)$ \\
4 & $4(2 \%)$ \\
5 & $1(0 \%)$ \\
\hline
\end{tabular}


Dengan menggunakan data testing sebanyak 205 (25\%) diperoleh 4 cluster yakni cluster-1 berjumlah 195 (95\%), cluster-2 berjumlah 3 (1\%), cluster-3 berjumlah $2(1 \%)$, cluster-4 berjumlah 4 (2\%). Pada cluster-5 hanya berjumlah 1 anggota $(1 \%)$,, sehingga dalam hal ini, tidak terbentuk cluster, dengan demikian jumlah cluster yang terbentuk hanyalah 4 cluster.

Visualisasi Hasil Clustering dengan alogritma Agglomerative Hierarchical Clustering jika disajikan dengan dendogram dari data training dengan melibatkan 205 data disajikan pada Gambar 1 berikut

Gambar 1: Dendogram untuk visualisasi hasil clustering dengan Algoritma AHC untuk data testing sebanyak $205(25 \%)$ record data

2. Data training sebanyak $50 \%$, dibentuk 5 cluster disajikan pada Tabel 5.

Tabel 5: Hasil clustering data training sebanyak $50 \%$

\begin{tabular}{cl}
\hline Cluster ke- & \multicolumn{1}{c}{$\begin{array}{c}\text { Jumlah anggota } \\
\text { cluster }\end{array}$} \\
\hline 1 & $393(96 \%)$ \\
2 & $4(1 \%)$ \\
3 & $6(1 \%)$ \\
4 & $7(2 \%)$ \\
5 & $1(0 \%)$ \\
\hline
\end{tabular}

Dengan menggunakan data testing sebanyak 411 (50\%) diperoleh 4 cluster yakni cluster-1 berjumlah 393 (95\%), cluster-2 berjumlah 4 (1\%), cluster-3 berjumlah $6(1 \%)$, cluster-4 berjumlah 7 (2\%). Pada cluster-5 hanya berjumlah 1
(1\%), sehingga dalam hal ini, tidak terbentuk cluster, dengan demikian jumlah cluster yang terbentuk hanyalah berjumlah 4.

Visualisasi Hasil Clustering dengan alogritma Agglomerative Hierarchical Clustering jika disajikan dengan dendogram dari data training dengan melibatkan 411 data disajikan pada Gambar 2 berikut

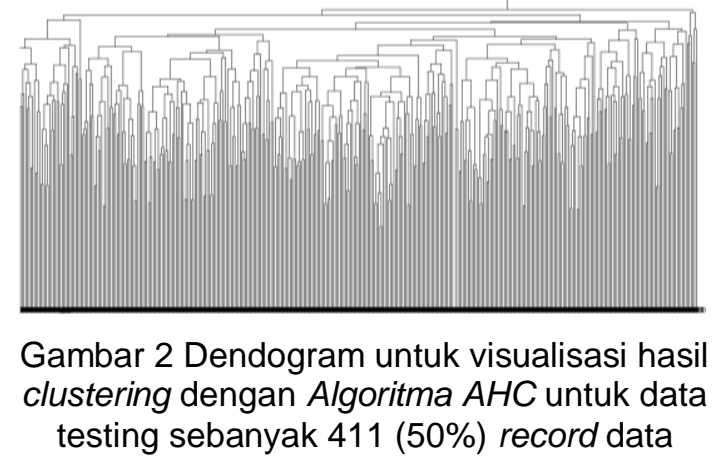

3. Data training sebanyak $75 \%$, dibentuk 5 cluster disajikan pada Tabel 6.

Tabel 6: Hasil clustering data training sebanyak $75 \%$

\begin{tabular}{cl}
\hline Cluster ke- & \multicolumn{1}{c}{$\begin{array}{c}\text { Jumlah anggota } \\
\text { cluster }\end{array}$} \\
\hline 1 & $557(90 \%)$ \\
2 & $30(5 \%)$ \\
3 & $3(0 \%)$ \\
4 & $20(3 \%)$ \\
5 & $6(1 \%)$ \\
\hline
\end{tabular}

Dengan menggunakan data testing sebanyak $616(50 \%)$ diperoleh 5 cluster yakni cluster-1 berjumlah 557 (90\%), cluster-2 berjumlah 30 (5\%), cluster-3 berjumlah $3(0 \%)$, cluster-4 berjumlah 20 (3\%). Pada cluster-5 berjumlah $6(1 \%)$,

Visualisasi Hasil Clustering dengan alogritma Agglomerative Hierarchical Clustering jika disajikan dengan dendogram dari data training dengan melibatkan 616 data disajikan pada Gambar 3 berikut 


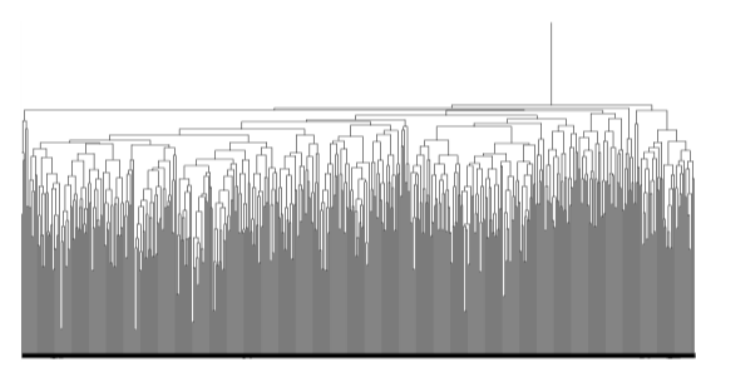

Gambar 3 Dendogram untuk visualisasi hasil clustering dengan Algoritma $A H C$ untuk data testing sebanyak $616(75 \%)$ record data

4. Data testing sebanyak $100 \%$, dibentuk 5 cluster dapat dilihat pada Tabel 7.

Tabel 7: Hasil clustering data training sebanyak $100 \%$

\begin{tabular}{cl}
\hline Cluster ke- & \multicolumn{1}{c}{$\begin{array}{c}\text { Jumlah anggota } \\
\text { cluster }\end{array}$} \\
\hline 1 & $806(98 \%)$ \\
2 & $5(1 \%)$ \\
3 & $9(1 \%)$ \\
4 & $1(0 \%)$ \\
5 & $1(0 \%)$ \\
\hline
\end{tabular}

Dengan menggunakan data testing sebanyak $822(100 \%)$ diperoleh 3 cluster yakni cluster-1 berjumlah 806 (98\%), cluster-2 berjumlah 5 (1\%), cluster-3 berjumlah 9 (1\%). Pada cluster-4 dan cluster-5 masing-masing hanya beranggotakan $1(0 \%)$, sehingga dalam hal ini cluster tidak terbentuk. Dengan demikian jumlah cluster yang terbentuk hanyalah 3.

Visualisasi Hasil Clustering dengan alogritma Agglomerative Hierarchical Clustering jika disajikan dengan dendogram dari data testing dengan melibatkan 822 data disajikan pada Gambar 4 berikut.

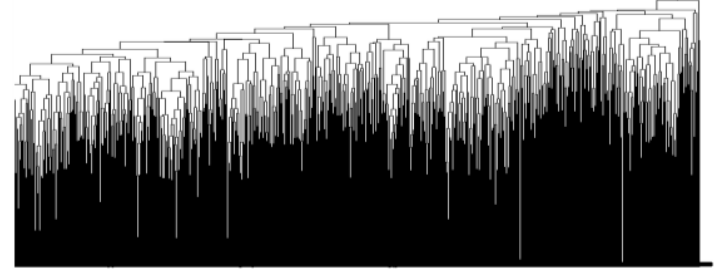

Gambar 4 Dendogram untuk visualisasi hasil clustering dengan Algoritma $A H C$ untuk data testing sebanyak 822 record data.

\section{KESIMPULAN}

1. Algoritma clustering agglomerative hierarchical clustering average linkage merupakan algoritma unsupervised learning dengan menggabungkan dua cluster dan seterusnya menjadi cluster baru berdasarkan similarity yang ditentukan menggunakan jarak Euclidean dengan kriteria rata-rata jarak seluruh individu dalam cluster yang lain.

2. Dengan menggunakan data testing sebanyak $822(100 \%)$ diperoleh 3 cluster yakni cluster-1 berjumlah 806 (98\%), cluster-2 berjumlah $5(1 \%)$, cluster-3 berjumlah 9 (1\%). Pada cluster-4 dan cluster-5 masing-masing hanya beranggotakan $1 \quad(0 \%)$, sehingga dalam hal ini cluster tidak terbentuk. Dengan demikian jumlah cluster yang terbentuk hanyalah 3 .

\section{DAFTAR PUSTAKA}

Barakbah, A.R., 2006. Clustering: workshop data mining 18-20 juli 2006. Jurusan Teknologi Informasi Politeknik Elektronika Negeri Semarang.

Hornick, F.M., Marcade, E. \& Venkayala, S. 2007. Java data mining: strategy, standard, and practice: a practical guide for architecture, design, and 
JUSTINDO (Jurnal Sistem \& Teknologi Informasi Indonesia), Vol. 4, No. 1, Februari 2019

implementation. San Fransisco:

Elsevier. 